\title{
Effect of L-Carnitine in Patients With Liver Cirrhosis on Energy Metabolism Using Indirect Calorimetry: A Pilot Study
}

\author{
Yoshiyuki Sakai ${ }^{a}$, Hiroki Nishikawa ${ }^{a}$, Hirayuki Enomoto ${ }^{a}$, b, Kazunori Yoha, Yoshinori Iwata ${ }^{a}$, \\ Kunihiro Hasegawa ${ }^{\mathrm{a}}$, Chikage Nakano ${ }^{\mathrm{a}}$, Kyohei Kishino ${ }^{\mathrm{a}}$, Yoshihiro Shimono ${ }^{\mathrm{a}}$, Ryo Takata ${ }^{\mathrm{a}}$, \\ Takashi Nishimura ${ }^{a}$, Nobuhiro Aizawa ${ }^{a}$, Naoto Ikeda ${ }^{a}$, Tomoyuki Takashima ${ }^{a}$, Akio Ishii ${ }^{a}$, \\ Hiroko Iijima $^{\text {a }}$, Shuhei Nishiguchi ${ }^{a}$
}

\begin{abstract}
Background: L-carnitine supplementation has been suggested to show several favorable effects on patients with liver cirrhosis (LC). However, there have been no reports regarding the effect of L-carnitine on energy metabolism in patients with LC using indirect calorimetry which is a well-established method for assessing the degree of liver malnutrition. We examined the effect of L-carnitine in patients with LC on energy metabolism using indirect calorimetry.
\end{abstract}

Methods: A total of $13 \mathrm{LC}$ patients who are scheduled to be treated with L-carnitine $(1,800 \mathrm{mg}$ /day) were analyzed in this study. None of the patients previously received L-carnitine. An evaluation of the nutritional status was performed at the initiation of L-carnitine therapy and after 4 weeks of L-carnitine therapy. We evaluated the effect of L-carnitine on the nutritional status and energy metabolism by comparing various clinical variables at these two time points. In addition, the changes in the nutritional status of the patients were also evaluated using indirect calorimetry.

Results: After 4 weeks of L-carnitine treatment, for all cases, the mean substrate oxidation rates of carbohydrate $(\% \mathrm{C})$ increased from $37.6 \%$ to $48.2 \%$, the mean substrate oxidation rates of fat $(\% \mathrm{~F})$ decreased from $40.2 \%$ to $31.9 \%$ and the mean substrate oxidation rates of protein $(\% \mathrm{P})$ decreased from $22.2 \%$ to $19.9 \%$. In a subgroup analysis of patients with baseline non-protein respiratory quotient $(\mathrm{npRQ})<0.85$, the mean $\% \mathrm{C}$ increased from $15.3 \%$ to $34.2 \%$, the mean $\% \mathrm{~F}$ decreased from $59.9 \%$ to $45.1 \%$, and the mean $\% \mathrm{P}$ decreased from $24.8 \%$ to $20.6 \%$. After 4 weeks of L-carnitine treatment, for all cases $(n=13)$, the mean value of npRQ increased in comparison with the baseline levels, although the difference was not significant $(0.868 \pm 0.060$ vs. $0.838 \pm 0.097, \mathrm{P}=0.19)$. Conversely, in patients with baseline $n p R Q<0.85$, the $n p R Q$ value significantly increased after 4 weeks treatment of L-carnitine compared

Manuscript accepted for publication September 13, 2016

aDivision of Hepatobiliary and Pancreatic Disease, Department of Internal Medicine, Hyogo College of Medicine, Nishinomiya, Hyogo 663-8501, Japan ${ }^{\mathrm{b}}$ Corresponding Author: Hirayuki Enomoto, Division of Hepatobiliary and Pancreatic Disease, Department of Internal Medicine, Hyogo College of Medicine, Mukogawa-cho 1-1, Nishinomiya, Hyogo 663-8501, Japan.

Email: enomoto@hyo-med.ac.jp

doi: http://dx.doi.org/10.14740/jocmr2734w with the baseline levels $(0.827 \pm 0.030$ vs. $0.760 \pm 0.043, \mathrm{P}=0.016)$.

Conclusion: L-carnitine supplementation can be useful for improving energy metabolism, especially in patients who have an advanced LC status and lower baseline npRQ values.

Keywords: Liver cirrhosis; L-carnitine; Indirect calorimetry; Nonprotein respiratory quotient; Energy metabolism

\section{Introduction}

The liver is the major organ for the metabolism of three major nutrients: protein, fat, and carbohydrates [1-3]. Liver cirrhosis (LC), which develops over a long period of time due to chronic inflammation such as hepatitis virus infection, is frequently complicated with protein-energy malnutrition (PEM) $[1,2,4,5]$. PEM is one of the most common complications in LC patients and it is closely associated with a high morbidity and mortality in patients with LC $[1,2,4,5]$.

Carnitine ( $\beta$-hydroxy- $\gamma$-N-trimethylaminobutyric acid) is widely distributed in food from animal sources. In humans, $75 \%$ of carnitine is obtained from the diet [6]. L-carnitine (4-Ntrimethyl ammonium 3-hydroxybutyric acid; the biologically active stereoisomer), which is involved in $\beta$-oxidation of fatty acids, is a conditionally synthesized nutrient from amino acids methionine and lysine in the brain, liver and kidney [6-8]. It is largely obtained from meat and dairy products [6-8]. Carnitine is responsible for transporting fatty acids into the mitochondria and it is involved in energy production by fat burning associated with $\beta$-oxidation $[6,9]$. L-carnitine is a derivative with high bioactivity in carnitine derivatives $[9,10]$. L-carnitine is a required nutrient in energy production and its deficiency is known to decrease energy availability in vital organs, especially in the liver $[8,11]$. Carnitine deficiency has been demonstrated to be linked to LC $[11,12]$. The administration of L-carnitine has been suggested to be a safe alternative treatment for LC patients. In the field of clinical practice, Malaguarnera reported that LC patients treated with L-carnitine showed greater reductions in serum ammonia levels as well as improvements in neuropsychological functioning in comparison with placebo [13]. On the other hand, Nakanishi et al demonstrated in their prospective study 
Table 1. Changes of Parameters Before and After 4 Weeks of L-Carnitine Therapy $(n=13)$

\begin{tabular}{llll}
\hline Variables & Baseline & At 4 weeks & P value $^{\mathbf{a}}$ \\
\hline Total carnitine $(\mu \mathrm{mol} / \mathrm{L})$ & $71.0 \pm 14.7$ & $105.5 \pm 30.0$ & $<0.001$ \\
\hline Free carnitine $(\mu \mathrm{mol} / \mathrm{L})$ & $54.5 \pm 13.8$ & $77.9 \pm 23.1$ & $<0.001$ \\
\hline Acyl carnitine $(\mu \mathrm{mol} / \mathrm{L})$ & $16.5 \pm 3.9$ & $27.6 \pm 9.0$ & $<0.001$ \\
\hline Non-protein respiratory quotient & $0.838 \pm 0.097$ & $0.868 \pm 0.060$ & 0.19 \\
\hline Rest energy expenditure $(\mathrm{kcal} / \mathrm{day})$ & $1,402.4 \pm 239.1$ & $1,379.9 \pm 265.3$ & 0.33 \\
\hline$\% \mathrm{C}$ & $37.6 \pm 30.0$ & $48.2 \pm 18.3$ & 0.12 \\
\hline \%F & $40.2 \pm 26.6$ & $31.9 \pm 23.7$ & 0.20 \\
\hline$\% \mathrm{P}$ & $22.2 \pm 15.3$ & $19.9 \pm 15.9$ & 0.48 \\
\hline Free fatty acid $(\mu \mathrm{Eq} / \mathrm{L})$ & $669.6 \pm 198.1$ & $846.2 \pm 192.5$ & 0.003 \\
Total cholesterol $(\mathrm{mg} / \mathrm{dL})$ & $171.8 \pm 43.3$ & $177.2 \pm 45.5$ & 0.16 \\
Triglyceride $(\mathrm{mg} / \mathrm{dL})$ & $66.1 \pm 25.3$ & $70.4 \pm 33.8$ & 0.19 \\
\hline Body weight $(\mathrm{kg})$ & $62.7 \pm 13.6$ & $63.0 \pm 13.8$ & 0.09 \\
\hline Serum albumin $(\mathrm{g} / \mathrm{dL})$ & $3.22 \pm 0.50$ & $3.29 \pm 0.58$ & 0.32 \\
\hline Serum prealbumin $(\mathrm{mg} / \mathrm{dL})$ & $9.85 \pm 2.74$ & $10.12 \pm 3.33$ & 0.41 \\
\hline BCAA to tyrosine ratio & $3.16 \pm 0.87$ & $3.35 \pm 1.14$ & 0.49 \\
\hline Fasting blood glucose $(\mathrm{mg} / \mathrm{dL})$ & $111.5 \pm 19.2$ & $113.2 \pm 19.2$ & 0.57 \\
\hline IRI $(\mu \mathrm{U} / \mathrm{mL})$ & $14.6 \pm 10.2$ & $12.1 \pm 7.5$ & 0.17 \\
\hline HOMA-IR & $3.97 \pm 2.75$ & $3.36 \pm 2.04$ & 0.23 \\
\hline Serum ammonia $(\mu \mathrm{g} / \mathrm{dL})$ & $65.8 \pm 49.1$ & $61.4 \pm 45.4$ & 0.53 \\
\hline
\end{tabular}

Data are presented as mean \pm standard deviation. \%C: substrate oxidation rates of carbohydrate; \%F: substrate oxidation rates of fat; \%P: substrate oxidation rates of protein; BCAA: branched chain amino acid; IRI: immune reactive insulin; HOMA-IR: homeostasis model assessment-insulin resistance. ${ }^{\text {aPaired }} t$-test.

that L-carnitine reduces muscle cramps in LC patients [14].

Indirect calorimetry is a well-established method for assessing the degree of liver malnutrition as it provides non-protein respiratory quotients (npRQ) and rest energy expenditure (REE) as useful markers to estimate energy metabolism [15]. Particularly, LC patients with npRQ of less than 0.85 had a significantly poorer survival as compared with those with npRQ of 0.85 or more [15]. Energy metabolism in patients with LC is characterized by increased energy consumption compared with healthy individuals, even at rest [15]. However, to the best of our knowledge, there have been no reports regarding the effect of L-carnitine on energy metabolism in patients with LC using indirect calorimetry. In the present study, we examined the effect of L-carnitine in patients with LC on energy metabolism using indirect calorimetry.

\section{Patients and Methods}

\section{Patients}

A total of $14 \mathrm{LC}$ patients who were scheduled to be treated with L-carnitine between December 2014 and February 2015 at the Division of Hepatobiliary and Pancreatic Disease, Department of Internal Medicine, Hyogo College of Medicine, Hyogo, Japan, were enrolled in this study. None of the patients previously received L-carnitine. LC was diagnosed using laboratory parameters or radiological findings. Among the patients, one patient developed rupture of esophageal varices after registration in this trial and was excluded from the current analysis. Thus, a total of 13 patients were analyzed in this study.

An evaluation of the nutritional status using indirect calorimetry was performed at the initiation of L-carnitine therapy and after 4 weeks of L-carnitine therapy in an outpatient basis. All patients received L-carnitine $(600 \mathrm{mg})$ three times a day $(1,800 \mathrm{mg} /$ day $)$ for at least 4 weeks. Laboratory data were also analyzed at the initiation of L-carnitine therapy and after 4 weeks of L-carnitine therapy. We prospectively evaluated the effect of L-carnitine on the nutritional status and energy metabolism by comparing variables at these two time points.

The ethics committee of our hospital approved the current study protocol (No. 1758) and this study protocol complied with all of the provisions of the Declaration of Helsinki. Written informed consent was obtained from all subjects prior to L-carnitine therapy.

\section{Indirect calorimetry}

The parameters measured by indirect calorimetry were carbon dioxide production per minute $\left(\mathrm{VCO}_{2}\right)$ and oxygen consumption per minute $\left(\mathrm{VO}_{2}\right)$. Total urinary excretion of nitrogen (UN) was measured as reported previously $[15,16]$. npRQ, REE, 

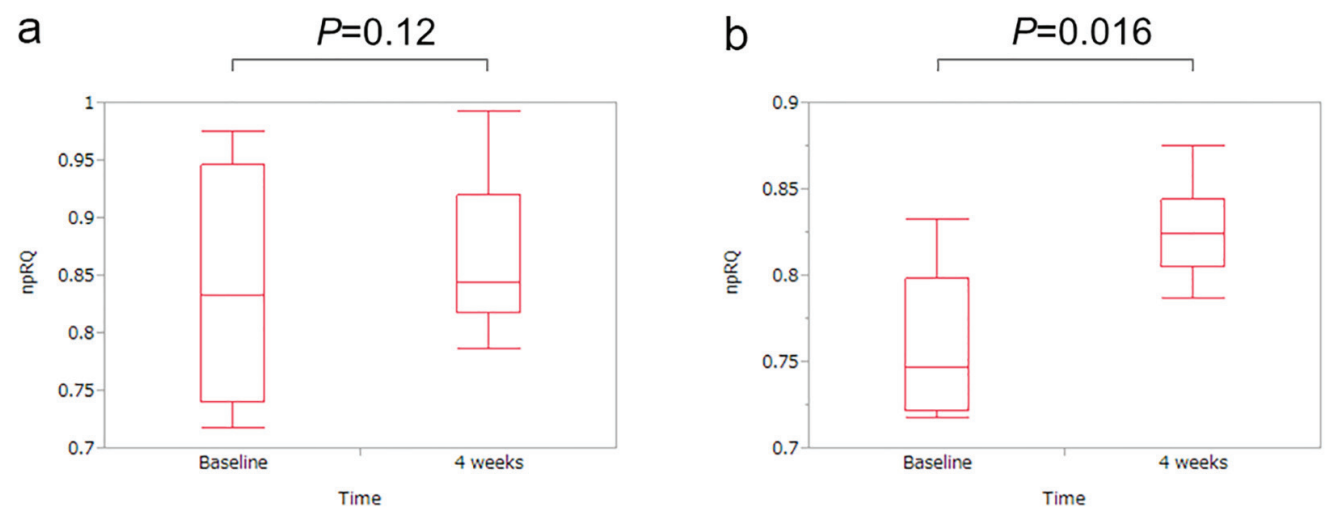

Figure 1. Changes in the non-protein respiratory quotient (npRQ) before and after 4 weeks of L-carnitine therapy. (a) For all cases $(n=13)$, the $n p R Q$ value at 4 weeks increased as compared with the baseline levels, although the difference was not significant $(P=0.12)$. (b) In patients with baseline $n p R Q<0.85(n=7)$, the $n p R Q$ value significantly increased as compared with the baseline levels after 4 weeks of $L$-carnitine treatment $(P=0.016)$.

and substrate oxidation rates of fat $(\% \mathrm{~F})$, carbohydrate $(\% \mathrm{C})$ and protein $(\% \mathrm{P})$ were calculated using the following formulas: 1$) \mathrm{npRQ}=\left(1.44 \mathrm{VCO}_{2}-4.890 \mathrm{UN}\right) /\left(1.44 \mathrm{VO}_{2}-6.04 \mathrm{UN}\right)$; 2) $\mathrm{REE}(\mathrm{kcal} /$ day $\left.)=5.50 \mathrm{VO}_{2}+1.76 \mathrm{VCO}_{2}-1.99 \mathrm{UN} ; 3\right) \mathrm{F}$ $\left.(\mathrm{g} / 24 \mathrm{~h})=2.432 \mathrm{VO}_{2}+2.432 \mathrm{VCO}_{2}-1.943 \mathrm{UN} ; 4\right) \mathrm{C}(\mathrm{g} / 24 \mathrm{~h})=$ $\left.5.926 \mathrm{VO}_{2}+4.189 \mathrm{VCO}_{2}-2.539 \mathrm{UN} ; 5\right) \mathrm{P}(\mathrm{g} / 24 \mathrm{~h})=6.250 \mathrm{UN}$; 6) $\% \mathrm{~F}=9.46 \mathrm{~F} / \mathrm{REE} \times 100 ; 7) \% \mathrm{C}=4.18 \mathrm{C} / \mathrm{REE} \times 100$; and 8$)$ $\% \mathrm{P}=4.32 \mathrm{P} / \mathrm{REE} \times 100[15,17-19]$. REE was determined in the morning after an overnight fast $(12 \mathrm{~h})$.

\section{Statistical analysis}

Continuous variables were compared by a paired $t$-test. Data were analyzed using the JMP software program for Microsoft Windows. Data were expressed as the mean \pm standard deviation (SD). A P value less than 0.05 was considered to be statistically significant.

\section{Results}

\section{Baseline characteristics}

The subjects included eight males and 5 females. The mean \pm SD age was $67.2 \pm 13.1$ years. The etiologies of LC were chronic hepatitis $\mathrm{B}$ virus infection in one patient, chronic hepatitis $\mathrm{C}$ virus infection in seven, alcoholic in three and others in two. Regarding the Child-Pugh classification, there were six patients with Child-Pugh A, five with Child-Pugh B and two with Child-Pugh $\mathrm{C}$. None of the patients were complicated with hepatocellular carcinoma.

\section{Changes in parameters before and after 4 weeks of $L$ - carnitine therapy}

After 4 weeks of L-carnitine treatment, total carnitine $(\mathrm{P}<$
0.001), free carnitine $(\mathrm{P}<0.001)$, acyl carnitine $(\mathrm{P}<0.001)$ and free fatty acid $(\mathrm{P}=0.004)$ significantly increased as compared with the baseline levels. The mean value of npRQ at 4 weeks increased, although the difference was not significant ( $\mathrm{P}$ $=0.19$, Table 1 and Fig. 1a).

Next, we performed a subgroup analysis of patients with baseline $n p R Q<0.85(n=7)$, since $n p R Q<0.85$ has been reported to be an adverse predictive factor in LC patients, as mentioned above [15]. After 4 weeks of L-carnitine treatment, total carnitine $(\mathrm{P}=0.001)$, free carnitine $(\mathrm{P}=0.001)$ and acyl carnitine $(\mathrm{P}=0.006)$ significantly increased as compared with the baseline levels. In addition, the $n p R Q$ value significantly increased as compared with the baseline levels $(\mathrm{P}=0.016$, Table 2 and Fig. 1b).

\section{Energy metabolism before and after L-carnitine therapy}

For all cases, the mean $\% \mathrm{C}$ was $37.6 \%$, the mean $\% \mathrm{~F}$ was $40.2 \%$ and the mean $\% \mathrm{P}$ was $22.2 \%$ during L-carnitine therapy. After 4 weeks of L-carnitine therapy, the mean $\% \mathrm{C}$ increased to $48.2 \%$, the mean $\% \mathrm{~F}$ decreased to $31.9 \%$ and the mean $\% \mathrm{P}$ decreased to $19.9 \%$, which indicated an improvement in energy metabolism (Table 1 and Fig. 2a). In the subgroup analysis of patients with baseline npRQ $<0.85$, the mean $\% \mathrm{C}$ was $15.3 \%$, the mean $\% \mathrm{~F}$ was $59.9 \%$ and the mean $\% \mathrm{P}$ was $24.8 \%$ during L-carnitine therapy. After 4 weeks of L-carnitine therapy, the mean $\% \mathrm{C}$ increased to $34.2 \%$, the mean $\% \mathrm{~F}$ decreased to $45.1 \%$ and the mean $\% \mathrm{P}$ decreased to $20.6 \%$, suggesting an improvement in energy metabolism (Table 2 and Fig. 2b).

\section{Changes in high-sensitivity C-reactive protein (hsCRP) levels between baseline and 4 weeks}

Previous studies demonstrated that hsCRP is a prognostic factor in patients with LC [20-22]. Thus, we tested the hsCRP concentration using stored sera at baseline and 4 weeks. For all patients, the hsCRP concentration at 4 weeks $(0.15 \pm 0.15$ 
Table 2. Changes of Parameters Before and After 4 Weeks of L-Carnitine Therapy in Patients With $n p R Q<0.85(n=7)$

\begin{tabular}{llll}
\hline Variables & Baseline & At 4 weeks & P value $^{\mathbf{a}}$ \\
\hline Total carnitine $(\mu \mathrm{mol} / \mathrm{L})$ & $65.9 \pm 16.5$ & $107.3 \pm 33.9$ & 0.001 \\
\hline Free carnitine $(\mu \mathrm{mol} / \mathrm{L})$ & $49.2 \pm 15.9$ & $76.5 \pm 25.7$ & 0.001 \\
\hline Acyl carnitine $(\mu \mathrm{mol} / \mathrm{L})$ & $16.7 \pm 3.0$ & $30.8 \pm 10.3$ & 0.006 \\
Non-protein respiratory quotient & $0.760 \pm 0.043$ & $0.827 \pm 0.030$ & 0.016 \\
Rest energy expenditure $(\mathrm{kcal} / \mathrm{day})$ & $1,368.1 \pm 195.2$ & $1,312.8 \pm 311.5$ & 0.25 \\
\%C & $15.3 \pm 15.4$ & $34.2 \pm 6.7$ & 0.019 \\
\%F & $59.9 \pm 16.9$ & $45.1 \pm 21.7$ & 0.073 \\
\%P & $24.8 \pm 17.3$ & $20.6 \pm 20.5$ & 0.49 \\
Free fatty acid $(\mu \mathrm{Eq} / \mathrm{L})$ & $761.0 \pm 147.7$ & $909.6 \pm 136.6$ & 0.069 \\
Total cholesterol $(\mathrm{mg} / \mathrm{dL})$ & $184.4 \pm 44.3$ & $185 \pm 48.0$ & 0.92 \\
Triglyceride $(\mathrm{mg} / \mathrm{dL})$ & $65.1 \pm 19.4$ & $65.4 \pm 21.1$ & 0.92 \\
Body weight $(\mathrm{kg})$ & $57.1 \pm 14.8$ & $57.2 \pm 14.7$ & 0.67 \\
Serum albumin $(\mathrm{g} / \mathrm{dL})$ & $3.06 \pm 0.39$ & $3.06 \pm 0.36$ & $>0.99$ \\
Serum prealbumin $(\mathrm{mg} / \mathrm{dL})$ & $9.1 \pm 3.0$ & $9.5 \pm 4.0$ & 0.45 \\
BCAA to tyrosine ratio & $2.97 \pm 0.72$ & $3.33 \pm 1.42$ & 0.47 \\
\hline Fasting blood glucose $(\mathrm{mg} / \mathrm{dL})$ & $111.7 \pm 25.5$ & $116.4 \pm 22.8$ & 0.34 \\
IRI $(\mu \mathrm{U} / \mathrm{mL})$ & $9.3 \pm 4.7$ & $9.3 \pm 4.3$ & 0.93 \\
\hline HOMA-IR & $2.51 \pm 1.23$ & $2.67 \pm 1.23$ & 0.43 \\
Serum ammonia $(\mu \mathrm{g} / \mathrm{dL})$ & $48.3 \pm 33.4$ & $41.6 \pm 16.6$ & 0.51 \\
\hline Pala & & & \\
\hline
\end{tabular}

Data are presented as mean \pm standard deviation. \%C: substrate oxidation rates of carbohydrate; \%F: substrate oxidation rates of fat; \%P: substrate oxidation rates of protein; BCAA: branched chain amino acid; IRI: immune reactive insulin; HOMA-IR: homeostasis model assessment-insulin resistance. aPaired $t$-test.

$\mathrm{mg} / \mathrm{dL})$ significantly decreased as compared with the hsCRP concentration at baseline $(0.20 \pm 0.17 \mathrm{mg} / \mathrm{dL})(\mathrm{P}=0.022$, Fig. $3 a)$. In patients with npRQ value $<0.85$, the hsCRP concentration at 4 weeks $(0.19 \pm 0.19 \mathrm{mg} / \mathrm{dL})$ tended to decrease as compared with the hsCRP concentration at baseline $(0.24 \pm$ $0.20 \mathrm{mg} / \mathrm{dL})(\mathrm{P}=0.11$, Fig. 3b).

\section{Discussion}

As mentioned above, several investigators reported that L-carnitine reduced serum ammonia levels, leading to an improvement in hepatic encephalopathy, and ameliorated LC-related neurological findings and LC-related clinical symptoms such as muscle cramps $[13,14,23]$. Moreover, several recent studies demonstrated that L-carnitine supplementation contributed to normalization of liver enzymes and an improvement in cytopenia during treatment for patients with chronic hepatitis $\mathrm{B}$ or $\mathrm{C}$ infection [24, 25]. However, there have been no reports regarding the effect of L-carnitine on energy metabolism using indirect calorimetry. Thus, there is an urgent need to clarify these issues. We therefore conducted this prospective pilot study. To the best of our knowledge, this is the first prospective study to assess the effect of L-carnitine therapy on energy metabolism in patients with LC.

In our study, the npRQ value tended to increase after 4 weeks of L-carnitine therapy as compared with the baseline levels for all cases, and in patients with baseline npRQ $<0.85$, the npRQ levels significantly increased compared with the baseline levels. Furthermore, after 4 weeks of L-carnitine therapy, the $\% \mathrm{C}$ increased, the $\% \mathrm{~F}$ decreased and the $\% \mathrm{P}$ decreased. These results indicated that L-carnitine supplementation leads to the improvement of energy metabolism, especially in patients with an advanced LC status such as Child-Pugh classification of B or C. L-carnitine therapy can be recommended for such patients. Our results may partly explain the reasons why clinical symptoms in advanced LC patients improve after L-carnitine therapy. On the other hand, in this study, the serum ammonia levels did not significantly decrease after L-carnitine therapy. This may be attributed to the small sample size.

Nakanishi et al previously demonstrated that the dose of L-carnitine was significantly associated with the percentages of patients with reduced muscle cramps [14]. In their cohort, they included patients who started at an L-carnitine dose of $900 \mathrm{mg} /$ day and those with $1,200 \mathrm{mg} /$ day. However, in our study, we set the dose of L-carnitine at 1,800 mg/day. Thus, the doses of L-carnitine vary between studies and the optimal dose of L-carnitine in LC patients remains unclear [14, 26]. Further investigations are required to clarify these issues.

A recent study revealed that free fatty acid (FFA) rose in parallel with increasing disease severity as defined by the Child-Pugh classification [18]. Another previous study demon- 

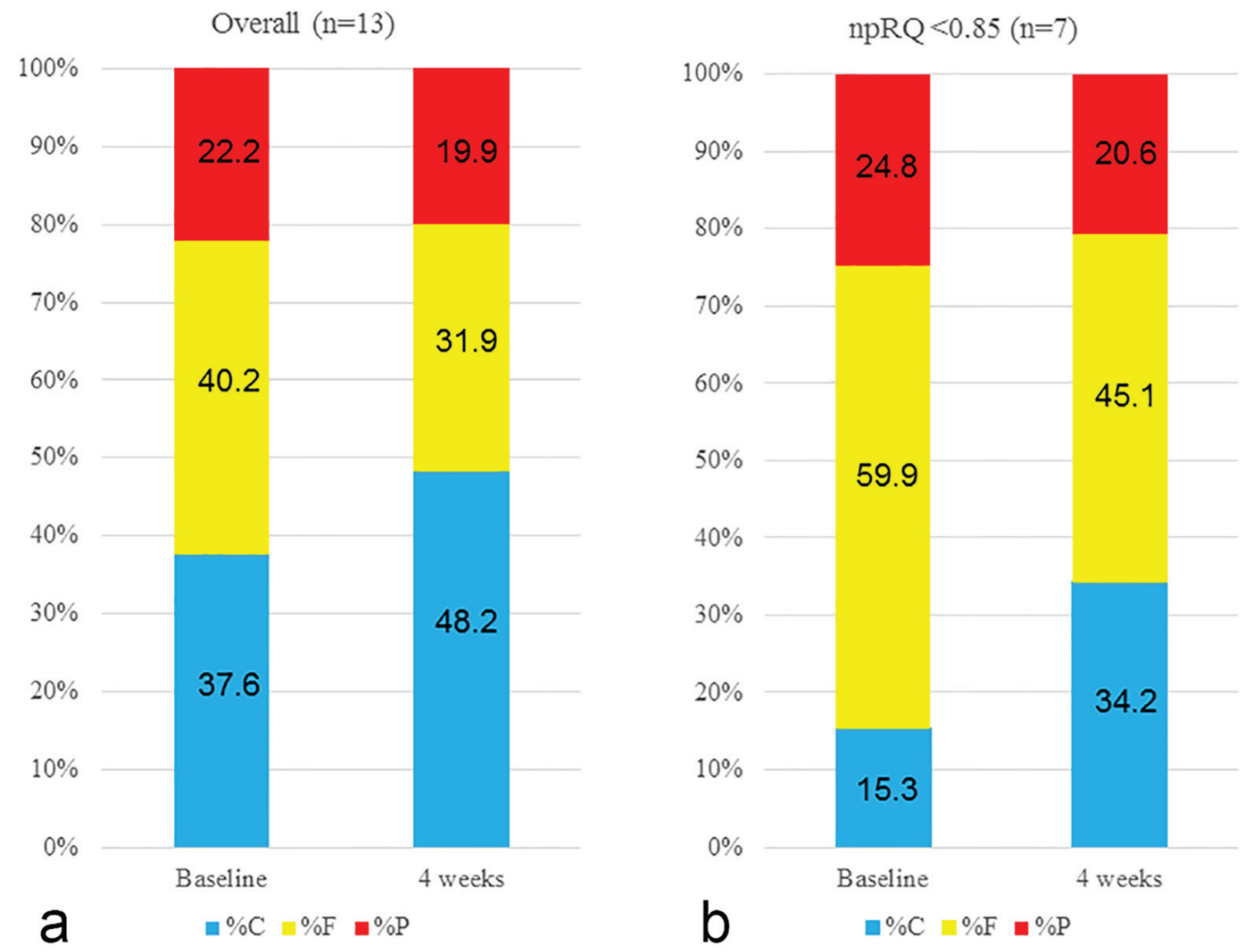

Figure 2. Changes in energy metabolism before and after L-carnitine therapy. (a) For all cases, the mean $\% \mathrm{C}$ was $37.6 \%$, the mean $\% \mathrm{~F}$ was $40.2 \%$ and the mean $\% \mathrm{P}$ was $22.2 \%$ at the time of L-carnitine therapy. After 4 weeks of L-carnitine therapy, the mean $\% \mathrm{C}$ increased to $48.2 \%$, the mean $\% \mathrm{~F}$ decreased to $31.9 \%$ and the mean $\% \mathrm{P}$ decreased to $19.9 \%$, which indicated an improvement in energy metabolism. (b) In a subgroup analysis of patients with baseline $\mathrm{npRQ}<0.85$, the mean $\% \mathrm{C}$ was $15.3 \%$, the mean $\% \mathrm{~F}$ was $59.9 \%$ and the mean $\% \mathrm{P}$ was $24.8 \%$ at the time of L-carnitine therapy. After 4 weeks of L-carnitine therapy, the mean \%C increased to $34.2 \%$, the mean $\% \mathrm{~F}$ decreased to $45.1 \%$ and the mean $\% \mathrm{P}$ decreased to $20.6 \%$, suggesting an improvement in energy metabolism. Data are expressed as mean values.
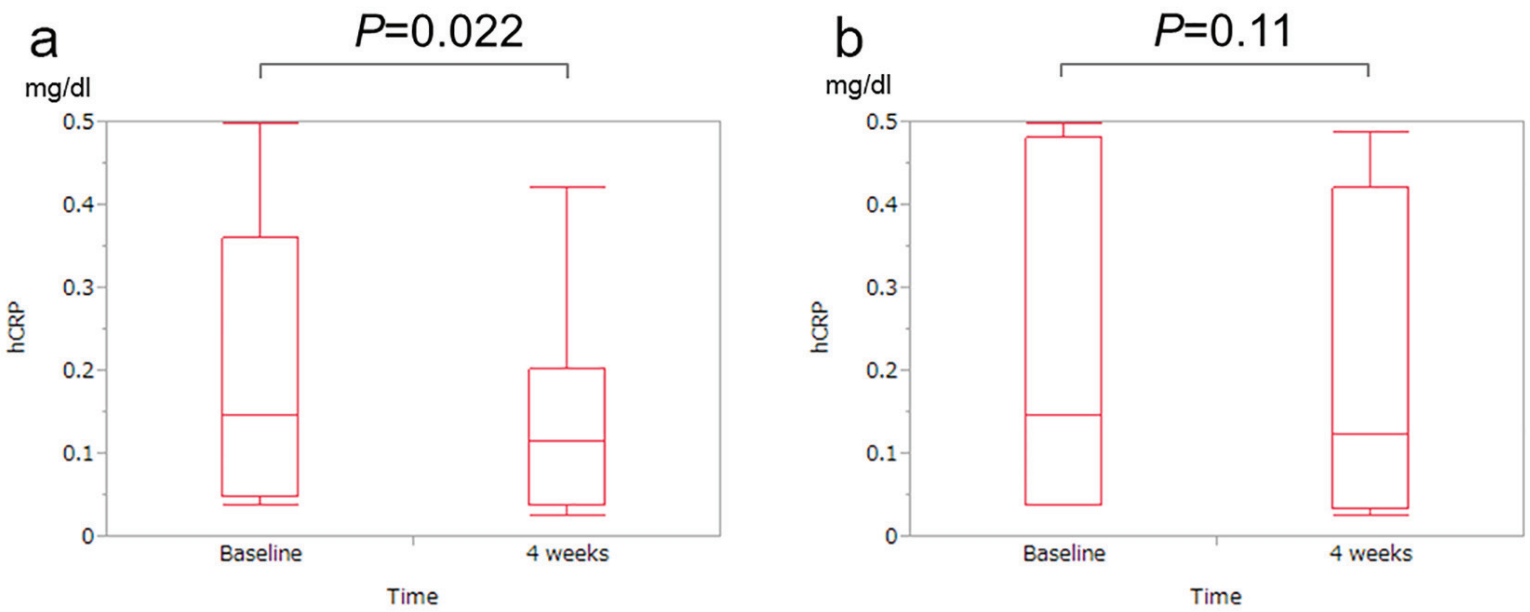

Figure 3. Changes in high-sensitivity C-reactive protein (hsCRP) levels between baseline and 4 weeks. (a) For all patients, the hsCRP level at 4 weeks significantly decreased as compared with the hsCRP level at baseline $(P=0.022)$. (b) In patients with a $n p R Q$ value $<0.85$, the hsCRP level at 4 weeks tended to decrease as compared with the hsCRP level at baseline $(P=0.11)$. 
strated that a higher serum FFA level may suggest the presence of nocturnal hypoglycemia in HCV-related compensated LC patients [27]. In view of this, the FFA value is expected to decrease after L-carnitine therapy. However, in our analysis, after 4-week treatment of L-carnitine, FFA significantly increased contrary to our expectations. Although the reason for this discrepancy is unclear, insulin resistance, which partly regulates fat metabolism, may be attributed to these discrepancies [28$31]$. Indeed, in our subjects with baseline homeostasis model assessment-insulin resistance (HOMA-IR) $\geq 2.5(n=9)$, FFA at 4 weeks after L-carnitine therapy significantly increased as compared with the baseline levels (mean value: $612 \mu \mathrm{Eq} / \mathrm{L}$ (baseline) and $807 \mu \mathrm{Eq} / \mathrm{L}$ (after 4-week treatment), $\mathrm{P}=0.013$ ). However, no definitive conclusion can be reached and further studies are needed to clarify these issues.

It is of note that the hsCRP concentration significantly decreased after 4 weeks of L-carnitine therapy for all cases. One potential reason for this result is that REE in 4 weeks decreased as compared with that at baseline (from 1,402.4 kcal/day (mean value, baseline) to $1,379.9 \mathrm{kcal} /$ day (mean value, 4 weeks)). Inadequate energy consumption in LC patients can cause higher systemic inflammation $[1,5,32]$. The improvement in energy metabolism by L-carnitine therapy may be associated with an improvement in systemic inflammation and may lead to ameliorating the clinical outcome in LC patients, as hsCRP has been reported to be a prognostic factor in LC patients [20-22].

Although our study has a limitation of a small sample size, we prospectively demonstrated that energy metabolism as defined by npRQ using indirect calorimetry improved after Lcarnitine therapy. According to the present results, we plan to conduct a future larger prospective study.

In conclusion, L-carnitine supplementation can be useful for improving energy metabolism, especially in advanced LC patients.

\section{Acknowledgments}

The authors would like to thank all medical staffs in our nutritional guidance room for data collection.

\section{Financial Disclosure}

Shuhei Nishiguchi received financial support from Ajinomoto Pharmaceuticals Co., LTD and Otsuka Pharmaceuticals Co., LTD.

\section{Abbreviations}

LC: liver cirrhosis; PEM: protein-energy malnutrition; npRQ: non-protein respiratory quotients; REE: rest energy expenditure; $\mathrm{VCO}_{2}$ : carbon dioxide production per minute; $\mathrm{VO}_{2}$ : oxygen consumption per minute; UN: rinary excretion of nitrogen; $\% \mathrm{~F}$ : substrate oxidation rates of fat; $\% \mathrm{C}$ : substrate oxidation rates of carbohydrate; $\% \mathrm{P}$ : substrate oxidation rates of protein; SD: standard deviation; hsCRP: high-sensitivity C-reactive protein; FFA: free fatty acid

\section{References}

1. Moriwaki H, Miwa Y, Tajika M, Kato M, Fukushima H, Shiraki M. Branched-chain amino acids as a protein- and energy-source in liver cirrhosis. Biochem Biophys Res Commun. 2004;313(2):405-409.

2. Charlton M. Branched-chain amino acid enriched supplements as therapy for liver disease. J Nutr. 2006;136(1 Suppl):295S-298S.

3. Nishikawa H, Osaki Y. Clinical significance of therapy using branched-chain amino acid granules in patients with liver cirrhosis and hepatocellular carcinoma. Hepatol Res. 2014;44(2):149-158.

4. Hanai T, Shiraki M, Nishimura K, Ohnishi S, Imai K, Suetsugu A, Takai K, et al. Sarcopenia impairs prognosis of patients with liver cirrhosis. Nutrition. 2015;31(1):193199.

5. Nishikawa H, Osaki Y. Liver Cirrhosis: Evaluation, Nutritional Status, and Prognosis. Mediators Inflamm. 2015;2015:872152.

6. Kendler BS. Carnitine: an overview of its role in preventive medicine. Prev Med. 1986;15(4):373-390.

7. Malaguarnera M. Carnitine derivatives: clinical usefulness. Curr Opin Gastroenterol. 2012;28(2):166-176.

8. Thangasamy T, Subathra M, Sittadjody S, Jeyakumar P, Joyee AG, Mendoza E, Chinnakkanu P. Role of L-carnitine in the modulation of immune response in aged rats. Clin Chim Acta. 2008;389(1-2):19-24.

9. Indiveri $\mathrm{C}$, Iacobazzi $\mathrm{V}$, Tonazzi A, Giangregorio N, Infantino $\mathrm{V}$, Convertini $\mathrm{P}$, Console $\mathrm{L}$, et al. The mitochondrial carnitine/acylcarnitine carrier: function, structure and physiopathology. Mol Aspects Med. 2011;32(46):223-233.

10. Jiang Q, Jiang G, Shi KQ, Cai H, Wang YX, Zheng MH. Oral acetyl-L-carnitine treatment in hepatic encephalopathy: view of evidence-based medicine. Ann Hepatol. 2013;12(5):803-809.

11. Krahenbuhl S, Reichen J. Carnitine metabolism in patients with chronic liver disease. Hepatology. 1997;25(1):148153.

12. Cave MC, Hurt RT, Frazier TH, Matheson PJ, Garrison RN, McClain CJ, McClave SA. Obesity, inflammation, and the potential application of pharmaconutrition. Nutr Clin Pract. 2008;23(1):16-34.

13. Malaguarnera M, Gargante MP, Cristaldi E, Vacante M, Risino C, Cammalleri L, Pennisi G, et al. Acetyl-L-carnitine treatment in minimal hepatic encephalopathy. Dig Dis Sci. 2008;53(11):3018-3025.

14. Nakanishi $H$, Kurosaki M, Tsuchiya K, Nakakuki N, Takada H, Matsuda S, Gondo K, et al. L-carnitine Reduces Muscle Cramps in Patients With Cirrhosis. Clin Gastroenterol Hepatol. 2015;13(8):1540-1543.

15. Tajika M, Kato M, Mohri H, Miwa Y, Kato T, Ohnishi H, Moriwaki H. Prognostic value of energy metabolism in patients with viral liver cirrhosis. Nutrition. 2002;18(3):229-234. 
16. Dickerson RN, Tidwell AC, Minard G, Croce MA, Brown RO. Predicting total urinary nitrogen excretion from urinary urea nitrogen excretion in multiple-trauma patients receiving specialized nutritional support. Nutrition. 2005;21(3):332-338.

17. Kato M, Miwa Y, Tajika M, Hiraoka T, Muto Y, Moriwaki H. Preferential use of branched-chain amino acids as an energy substrate in patients with liver cirrhosis. Intern Med. 1998;37(5):429-434.

18. Hanai T, Shiraki M, Nishimura K, Imai K, Suetsugu A, Takai K, Shimizu M, et al. Free fatty acid as a marker of energy malnutrition in liver cirrhosis. Hepatol Res. 2014;44(2):218-228.

19. Teramoto A, Yamanaka-Okumura H, Urano E, Nakamura-Kutsuzawa T, Sugihara K, Katayama T, Miyake H, et al. Comparison of measured and predicted energy expenditure in patients with liver cirrhosis. Asia Pac J Clin Nutr. 2014;23(2):197-204.

20. Mortensen C, Andersen O, Krag A, Bendtsen F, Moller S. High-sensitivity C-reactive protein levels predict survival and are related to haemodynamics in alcoholic cirrhosis. Eur J Gastroenterol Hepatol. 2012;24(6):619-626.

21. Cho Y, Park SY, Lee JH, Lee DH, Lee M, Yoo JJ, Choi $\mathrm{WM}$, et al. High-sensitivity $\mathrm{C}$-reactive protein level is an independent predictor of poor prognosis in cirrhotic patients with spontaneous bacterial peritonitis. J Clin Gastroenterol. 2014;48(5):444-449.

22. Cervoni JP, Thevenot T, Weil D, Muel E, Barbot O, Sheppard F, Monnet E, et al. C-reactive protein predicts short-term mortality in patients with cirrhosis. J Hepatol. 2012;56(6):1299-1304.

23. Vidot H, Carey S, Allman-Farinelli M, Shackel N. Systematic review: the treatment of muscle cramps in patients with cirrhosis. Aliment Pharmacol Ther. 2014;40(3):221232.

24. Jun DW, Kim BI, Cho YK, Kim HJ, Kwon YO, Park SY, Han SY, et al. Efficacy and safety of entecavir plus carni- tine complex $(\operatorname{GODEX}(\mathrm{R}))$ compared to entecavir monotherapy in patient with ALT elevated chronic hepatitis B: randomized, multicenter open-label trials. The GOAL study. Clin Mol Hepatol. 2013;19(2):165-172.

25. Malaguarnera M, Vacante M, Giordano M, Motta M, Bertino G, Pennisi M, Neri S, et al. L-carnitine supplementation improves hematological pattern in patients affected by HCV treated with Peg interferon-alpha 2 b plus ribavirin. World J Gastroenterol. 2011;17(39):4414-4420.

26. Cruciani RA, Revuelta M, Dvorkin E, Homel P, Lesage P, Esteban-Cruciani N. L-carnitine supplementation in patients with HIV/AIDS and fatigue: a double-blind, placebo-controlled pilot study. HIV AIDS (Auckl). 2015;7:6573.

27. Kawaguchi T, Itou M, Taniguchi E, Sakata M, Abe M, Koga H, Oriishi T, et al. Serum level of free fatty acids is associated with nocturnal hypoglycemia in cirrhotic patients with HCV infection: a pilot study. Hepatogastroenterology. 2011;58(105):103-108.

28. Asrih M, Jornayvaz FR. Metabolic syndrome and nonalcoholic fatty liver disease: Is insulin resistance the link? Mol Cell Endocrinol. 2015;41(8 Pt 1):55-65.

29. Pereira S, Shah A, George Fantus I, Joseph JW, Giacca A. Effect of N-acetyl-1-cysteine on insulin resistance caused by prolonged free fatty acid elevation. J Endocrinol. 2015;225(1):1-7.

30. Pereira S, Park E, Mori Y, Haber CA, Han P, Uchida T, Stavar L, et al. FFA-induced hepatic insulin resistance in vivo is mediated by PKCdelta, NADPH oxidase, and oxidative stress. Am J Physiol Endocrinol Metab. 2014;307(1):E34-46.

31. Birkenfeld AL, Shulman GI. Nonalcoholic fatty liver disease, hepatic insulin resistance, and type 2 diabetes. Hepatology. 2014;59(2):713-723.

32. Coltart I, Tranah TH, Shawcross DL. Inflammation and hepatic encephalopathy. Arch Biochem Biophys. 2013;536(2):189-196. 